Rev. Elet. em Gestão, Educação e Tecnologia Ambiental (e-ISSN: 2236-1170)

\title{
CARACTERIZAÇÃO DOS ESPAÇOS PÚBLICOS DE LAZER E A SATISFAÇÃO DOS USUÁRIOS NA ÁREA CENTRAL DE SANTA MARIA - RS
}

\author{
Cristhian Moreira Brum², Pedro Daniel da Cunha Kemerich², Anna Paula Batista Goldfeld³, \\ Fernando Ernesto Ucker ${ }^{4}$, Willian Fernando de Borba ${ }^{5}$
}

\begin{abstract}
${ }^{1}$ Professor do Departamento de Ciências Sociais Aplicadas da Universidade Regional Integrada do Alto Uruguai e das Missões - URI Campus de Frederico Westphalen - RS, Graduação em Arquitetura e Urbanismo pela Universidade Regional Integrada do Alto Uruguai e das Missões (URI - Campus de Santiago - RS), Pós-Graduação nível lato sensu em Gestão Ambiental pelo Centro Universitário Franciscano (UNIFRA) e Pós-Graduação nível stricto sensu em Engenharia Civil e Ambiental pela Universidade Federal de Santa Maria (UFSM). br.cristhian@hotmail.com

${ }^{2}$ graduação em Engenharia Ambiental pelo Centro Universitário Franciscano -UNIFRA (2005). Mestrado pela Universidade Federal de Santa Maria - UFSM, em Recursos Hídricos e Saneamento Ambiental (2008), Pós-Graduação em Engenharia de Segurança do Trabalho pelo Centro Universitário Franciscano - UNIFRA (2009) e é Doutorando do

Programa de Pós-Graduação em Engenharia Ambiental da Universidade Federal de Santa Catarina. eng.kemerich@yahoo.com.br

${ }^{3}$ Graduação em Engenheira Agrônoma - FESURV (2002), Mestranda em Solo e Água, na UFG. ana.govesa@hotmail.com

${ }^{4}$ Doutorando no curso de Agronomia da Universidade Federal de Goiás. Graduação em Engenharia Ambiental pelo Centro Universitário Franciscano - UNIFRA (2009), Mestrado em Engenharia do Meio Ambiente pela Universidade Federal de Goiás - GO. ferucker@hotmail.com

${ }^{5}$ Técnico em Agropecuária pela Universidade Federal de Santa Maria (2007). Aluno de Graduação do Curso de Engenharia Ambiental da Universidade Federal de Santa Maria (2009 - 2014). borba willian@hotmail.com
\end{abstract}

http://dx.doi.org/10.5902/223611707639

\section{RESUMO}

Os espaços públicos de lazer se constituem num importante elo entre o poder público e a comunidade, essencial para eventos e acontecimentos de importância social e histórica. Este trabalho apresenta a questão dos conflitos e relações destes espaços, procurando analisar seus aspectos quanto ao uso, circulações e acessibilidade destes locais de intervenção. Ainda, questionar a adequação do desenvolvimento urbano do município de Santa Maria - RS, a partir da avaliação da qualidade urbana sob a ótica dos espaços públicos de lazer, fazendo para isso um levantamento técnico sobre essas áreas. Utilizaram-se métodos quantitativos e qualitativos em relação aos espaços públicos de lazer existentes na área central, além de registros fotográficos do entorno dos determinados locais, que foram complementados com questionários aos usuários. Desse modo, o presente estudo e seus resultados servirão de subsídios ao Poder Público para as ações de planejamento e gestão destes espaços destinados à população, a fim de suprir as carências encontradas quanto ao aspecto de infraestrutura e controle da diversidade de espécies analisadas.

Palavras-chaves: Áreas verdes, espaços urbanos, qualidade ambiental. 
Rev. Elet. em Gestão, Educação e Tecnologia Ambiental (e-ISSN: 2236-1170)

\begin{abstract}
The public spaces of leisure constitute an important link between the government and the community, essential for events of social and historical importance. This work presents the issue of conflicts and relationships of these spaces, trying to analyze aspects regarding the use, circulation and accessibility of local intervention. Still, questioning the appropriateness of urban development in the municipality of Santa Maria - RS, based on the evaluation of quality from the perspective of urban public spaces for leisure, for making this a technical survey on these areas. Were used quantitative and qualitative methods in relation to existing public spaces for leisure in the central area, and photographic records of the surroundings of certain sites, which were supplemented with questionnaires to users. Thus, this study and its results will serve as subsidies to the Government for action planning and management of these spaces to the population in order to remedy the shortcomings found in the appearance of the control infrastructure and diversity of species.
\end{abstract}

Keywords: Green areas, urban spaces, environment quality.

\title{
INTRODUÇÃO
}

A problemática ambiental tem se tornado um assunto de importância para a vida das pessoas, e assim os espaços públicos de lazer tornam-se os principais ícones de defesa do meio ambiente pela sua degradação, e pelo exíguo espaço que lhes é destinado nos centros urbanos.

Segundo Romero (2001) e Neckel et al. (2009), as cidades têm como base composições com espaços construídos e composições de espaços não construídos, criando um sistema integrado que une o aglomerado urbano. Existem tipologias e nomenclaturas estabelecidas para os espaços não construídos: espaços livres, vazios, intersticiais, abertos, colocados, verdes, coletivos, neutros e espaços públicos. Estes tratamentos são reflexos da evolução das atribuições e das funções dos espaços exteriores.

No final do século XVIII, surgem os parques urbanos na Inglaterra, devido ao acentuado crescimento econômico. A fundamental importância foi à criação e aplicação de técnicas paisagísticas, as quais eram aplicadas aos parques urbanos. Já no século XIX, estes espaços verdes, chamados de jardins, tornavam-se freqüentes ao cotidiano e proporcionavam qualidade de vida, principalmente para os americanos e franceses, ou seja, eram estes espaços que permitiam o lazer e recreação da população (SCALISE, 2002).

Morris (1984) e Oliveira e Bitar (2009) usam a nomenclatura "recintos espaciais" para as diferentes categorias de praças com a intenção de distingui-las conforme o tráfego: espaços destinados ao tráfego, espaços pedonais e espaços residenciais. Esta classificação ressalta as diferenças que o "largo" e a "praça" irão adquirir na estrutura urbana.

O lazer, segundo Dumazedier (1973), é um conjunto de atividades que podem proporcionar repouso, divertimento, formação desinteressada após o individuo livrar-se das obrigações profissionais e familiares. Para Zamora et al. (2003) e Zanin et al. (2005) o lazer, atualmente, é uma necessidade da sociedade e assim se fez a partir do momento que as jornadas de trabalho foram determinadas e o tempo ócio passou a ser indispensável para o bem estar humano. Nesse contexto, os espaços urbanos funcionam como centros que possibilitam a prática do lazer como esportes, brincadeiras, danças, teatro, dentre outras formas de realizar a prática.

A proposta desta pesquisa foi visualizar detalhadamente os espaços públicos centrais de Santa Maria, município localizado no centro do Estado do Rio Grande do Sul - RS. Com isso, 
Rev. Elet. em Gestão, Educação e Tecnologia Ambiental (e-ISSN: 2236-1170)

permitiu a elucidação de questões técnico-ambientais e funcionais, de percepção de usuários e acessibilidade, que refletem na qualidade e uso de cada um desses espaços. De forma específica, a proposta de investigação foi trazer esta discussão para a realidade do município, com a análise dos espaços públicos de lazer existentes na área central, considerando que o Plano Diretor e as políticas públicas não possuem diretrizes que norteiem o manejo destes espaços.

\section{METODOLOGIA}

O trabalho trata-se de uma pesquisa descritiva e investigativa de caráter quantitativo e qualitativo. Os métodos utilizados foram levantamentos de arquivo e de campo, com o objetivo de obter resultados confiáveis através do cruzamento de dados dos aspectos estudados.

Foram feitas análises de sete espaços públicos de lazer, analisando os aspectos físicos (infraestrutura, equipamentos, mobiliário urbano e entorno), aspectos ambientais (medição de ruídos) e de uso (questionário com usuários), procedendo a um estudo individual de cada espaço e um comparativo geral destes espaços no bairro central.

O município estudado foi o de Santa Maria, localizado na parte central do Estado do Rio Grande do Sul, e apresenta uma população de 263.403 habitantes, distribuída em uma área de $1.780 \mathrm{Km}^{2}$ (IBGE, 2007). A área de estudo está na faixa denominada bairro centro da área urbana de Santa Maria, e compreende sete espaços de lazer, conforme a Figura 1.

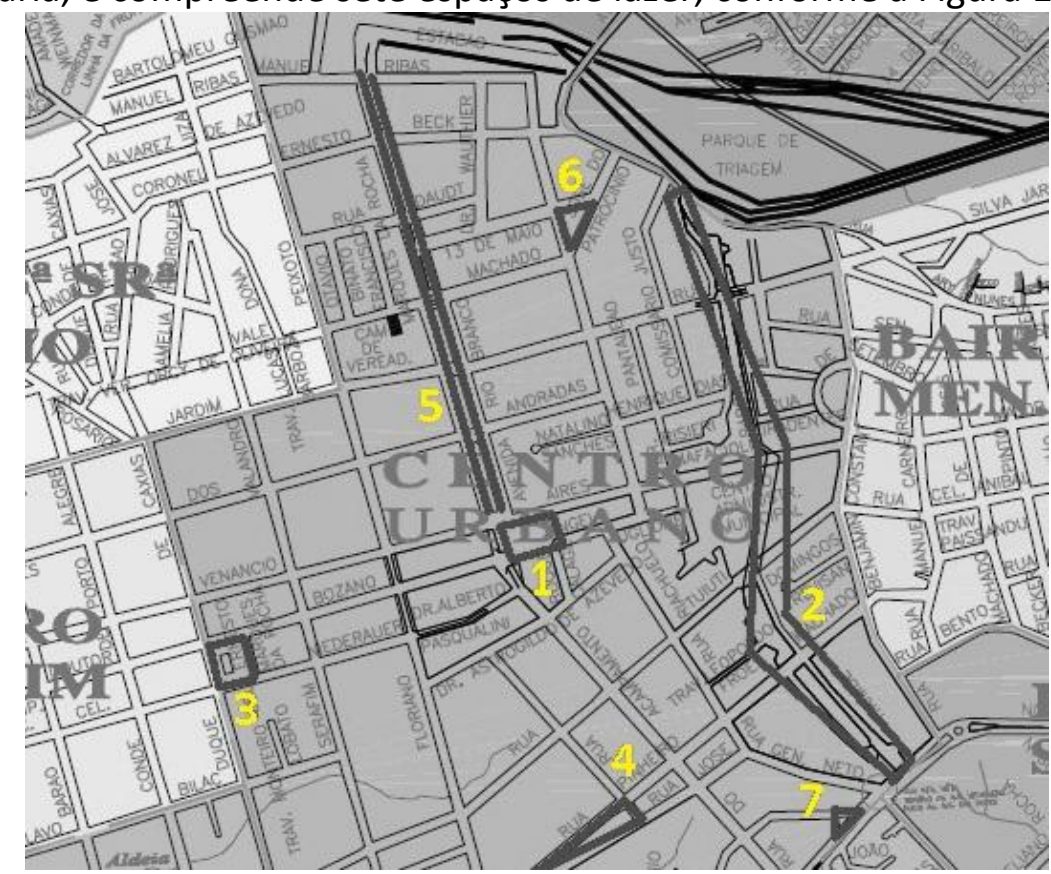

Figura 1. Localização dos Espaços Analisados na Área Central de Santa Maria. (1) Praça Saldanha Marinho; (2) Parque Itaimbé; (3) Praça Sarturnino de Brito; (4) Praça Roque Gonzáles;

(5) Canteiros Centrais da Av. Rio Branco; (6) Praça Cristóvão Colombo; (7) Largo Maçônico.

Foram obtidos dados e registros existentes dos sete espaços públicos de lazer analisados, com pesquisa em órgãos municipais. Obteve-se, portanto, cadastros, projetos técnicos e uma listagem dos locais com aprovações legais dos espaços destinados. Cabe observar que não existe um registro organizado destas áreas nos órgãos municipais. Foram feitas visitas in loco nas áreas estudadas para atualização e complementação dos dados existentes. 
Rev. Elet. em Gestão, Educação e Tecnologia Ambiental (e-ISSN: 2236-1170)

O levantamento de campo também foi realizado nos sete espaços estudados do município, tanto sob questões técnicas quanto do ponto de vista dos usuários, com o objetivo de verificar os usos e aferir quais os atributos espaciais estão conduzindo seus usuários a realizar determinadas atividades e como estes percebem e avaliam o espaço considerado. O estudo abordou as seguintes análises: o aspecto físico, o aspecto ambiental e o aspecto de uso e percepção dos espaços com questionário aos usuários.

Foram ainda levantados dados in loco sobre: localização e quantidade de árvores; tipo de pavimentação; barreiras físicas existentes nos caminhos e calçadas; fechamento espacial do entorno; quantidade, localização, material e conservação dos bancos, luminárias, lixeiras, orelhões, monumentos, chafarizes, brinquedos do playground; existência e estado de conservação de banheiros; localização de pontos de ônibus e táxis. Vias de transporte para deficientes e idosos.

O aspecto ambiental dos espaços foi analisado com medições de nível de ruído em diferentes horários. As medições foram realizadas em quatro períodos do dia: manhã, meio dia, tarde e noite. Estes horários foram escolhidos baseados em observação da quantidade de usuários durante o dia nestes espaços. Para as determinações de ruído foi utilizado um decibelímetro digital portátil - Modelo DEC-470 da marca INSTRUTHERM.

\section{Aplicação de Questionários aos Usuários}

A aplicação de questionário aos usuários permitiu coletar informações que revelaram sua opinião, comportamentos e reações emocionais, demonstrando a satisfação e a postura dos usuários em relação aos espaços públicos de lazer levantados. Sua elaboração foi orientada pelas variáveis a serem investigadas, objetivando a análise do grau de satisfação dos usuários e da percepção que eles têm daquele espaço. Para isto, foram elaboradas questões de fácil tratamento estatístico, porém limitadas quanto às respostas, e questões que possibilitaram coletar dados referentes aos sentimentos e sensações de cada usuário. As perguntas realizadas estão presentes no Quadro 1.

\begin{tabular}{|c|l|}
\hline & \multicolumn{1}{|c|}{ Questões } \\
\hline 1. & $\begin{array}{l}\text { Como você classifica a arborização do centro urbano do município de Santa } \\
\text { Maria? }\end{array}$ \\
\hline 2. & $\begin{array}{l}\text { Qual seu grau de satisfação em relação aos ambientes arborizados em Santa } \\
\text { Maria? }\end{array}$ \\
\hline 3. & $\begin{array}{l}\text { Ao observar a arborização central de Santa Maria, qual sua opinião quanto ao } \\
\text { planejamento da mesma? }\end{array}$ \\
\hline 4. & Quais as vantagens da arborização urbana? \\
\hline 5. & Quais as desvantagens da arborização urbana? \\
\hline 6. & Qual o turno diário que você costuma freqüentar este espaço público de lazer? \\
\hline 7. & $\begin{array}{l}\text { Qual o seu grau de satisfação quanto ao nível de ruído neste espaço ao seu } \\
\text { entorno? }\end{array}$ \\
\hline
\end{tabular}

Quadro 1.

Questionário aplicado aos usuários dos espaços públicos de lazer estudados. 
Rev. Elet. em Gestão, Educação e Tecnologia Ambiental (e-ISSN: 2236-1170)

\section{RESULTADOS E DISCUSSÕES}

De acordo com o levantamento os sete espaços públicos de lazer correspondem uma área total de 69.794,44 $\mathrm{m}^{2}$ com 1.103 espécies de porte arbóreo, obtendo uma média de uma espécie arbórea a cada 63,28 $\mathrm{m}^{2}$ na área central do município (SANTA MARIA, 2010). As espécies arbóreas predominantes em cada espaço de lazer constam no Quadro 2. Os espaços foram classificados conforme sua tipologia: parque, praça, largo e terreiro.

Essa classificação foi resultado de uma compilação de conceitos revisados de alguns autores, como Lamas (1990), Drew (1993), Kliass (1993), Silva (2003) e Ferreira (2003), resultando no seguinte critério para ser utilizado no presente trabalho: a praça é um espaço aberto público cercado de ruas por todos os lados, concebido como espaço intencional de encontros sociais e atividades de lazer.

\begin{tabular}{|c|c|}
\hline Espaço & Espécie Arbórea Predominante \\
\hline Praça Saldanha Marinho & Figueira (fícus elastica) \\
\hline Parque Itaimbé & Jacarandá Mimoso (jacaranda \\
mimosaefolia)
\end{tabular}

Sobre o levantamento dos níveis de ruídos dos espaços de lazer, a Norma NBR 10151:2000 (ABNT, 2000) recomenda que as medições devem ser efetuadas com medidor de nível sonoro, como especificado na IEC 651 Sonômetros. Deve ser utilizada a escala de compensação A e respostas de leitura rápida. O nível sonoro deve ser medido no local e hora de ocorrência do incômodo. No item 3.1.2.1 da norma, as medições no ambiente externo devem ser efetuadas a 1,2 $\mathrm{m}$ acima do solo e, no mínimo, a 1,5 m de paredes, edifícios e outras superfícies refletoras. Quando as circunstâncias exigirem, as medições podem ser efetuadas a diferentes alturas e próximo à paredes (por exemplo, 0,5 $\mathrm{m}$ em frente a uma janela aberta), desde que isto esteja especificado e levado em consideração. Os níveis de ruído medidos em determinadas faixas de horários são apresentados no Quadro 3.

\begin{tabular}{|c|c|c|c|}
\hline Espaço & Data & Horário & dB (A) \\
\hline \multirow{3}{*}{ Praça Saldanha Marinho } & \multirow{2}{*}{$16 / 09 / 2010$} & $15 \mathrm{~h} 05 \mathrm{~min}$ & 67,3 \\
\cline { 3 - 4 } & & $19 \mathrm{~h} 35 \mathrm{~min}$ & 60,9 \\
\cline { 3 - 4 } & \multirow{2}{*}{$17 / 09 / 2010$} & $08 \mathrm{~h} 16 \mathrm{~min}$ & 68,8 \\
\cline { 3 - 4 } & & $12 \mathrm{~h} 10 \mathrm{~min}$ & 64,3 \\
\hline \multirow{2}{*}{ Parque Itaimbé } & \multirow{2}{*}{$16 / 09 / 2010$} & $15 \mathrm{~h} 20 \mathrm{~min}$ & 54,0 \\
\cline { 3 - 4 } & & $20 \mathrm{~h} 00 \mathrm{~min}$ & 53,9 \\
\cline { 3 - 4 } & \multirow{2}{*}{$17 / 09 / 2010$} & $08 \mathrm{~h} 05 \mathrm{~min}$ & 62,3 \\
\cline { 3 - 4 } & & $12 \mathrm{~h} 20 \mathrm{~min}$ & 63,8 \\
\hline \multirow{2}{*}{ Praça Sarturnino de Brito } & \multirow{2}{*}{$16 / 09 / 2010$} & $14 \mathrm{~h} 55 \mathrm{~min}$ & 59,7 \\
\cline { 3 - 4 } & & $19 \mathrm{~h} 30 \mathrm{~min}$ & 71,4 \\
\hline
\end{tabular}


Rev. Elet. em Gestão, Educação e Tecnologia Ambiental (e-ISSN: 2236-1170)

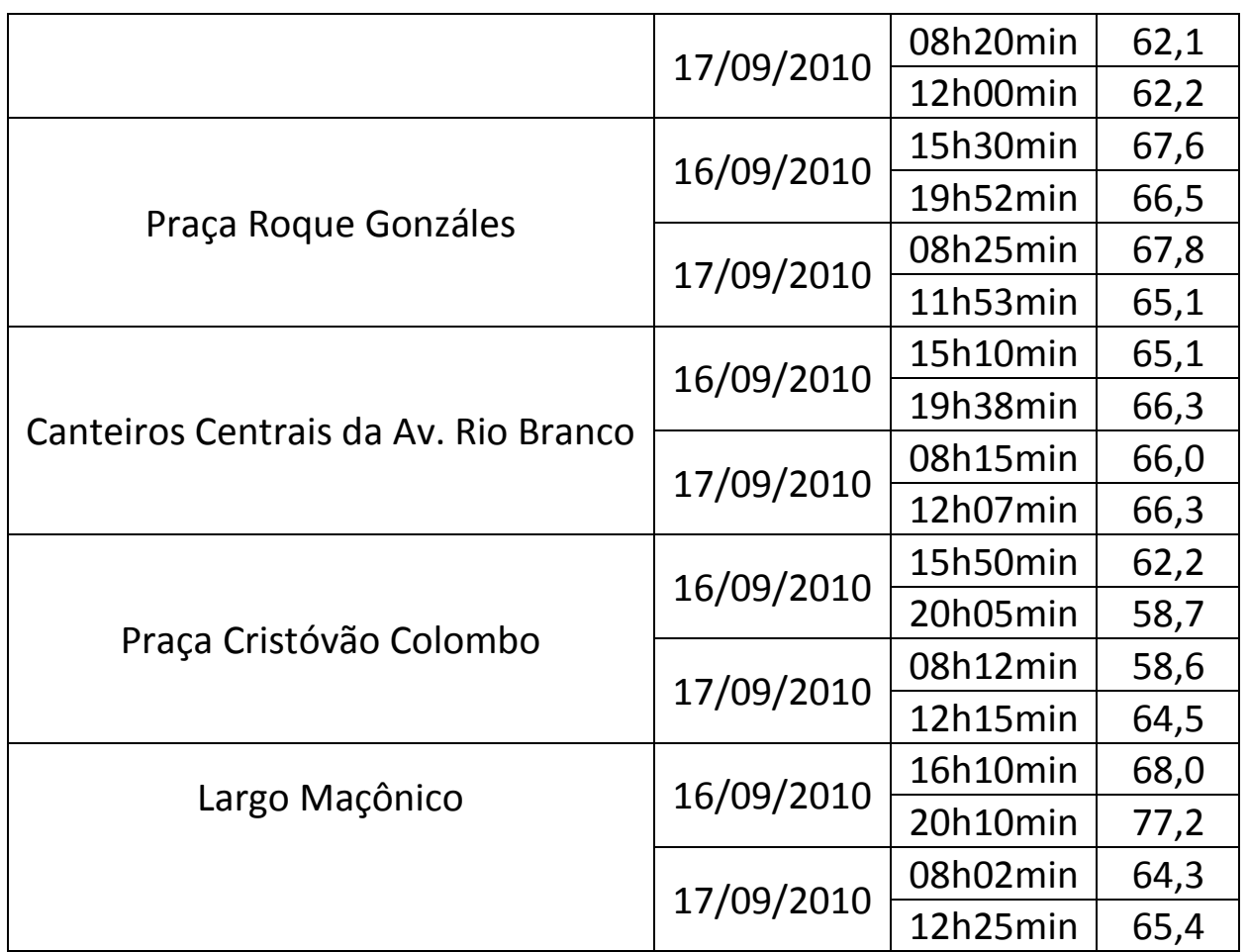

Quadro 3. Medição em dB (A) do nível de ruído em determinadas faixas de horário.

Os níveis de ruídos existentes estão parcialmente de acordo com a norma NBR 10151:2000 (ABNT, 2000), sendo que seu principal foco de ruído são os veículos que trafegam nas ruas que a delimitam, onde certamente nos horários de rush os ruídos são mais elevados por causa do aumento do número de carros. Existe um foco de ruído secundário proveniente da concentração de crianças no playground, mas que também está dentro dos parâmetros da norma e é esporádico ao longo do dia. Constatou-se que esta norma recomenda para área estritamente residencial urbana ou de hospitais ou de escolas valores de $d B(A)$ de 50 (diurno) e 45 (noturno), sendo coletado na Praça Roque Gonzales, em frente ao Hospital de Caridade de Santa Maria/RS dados de 65,1 até 67,8, verificando-se que está acima do permitido em norma.

O Código de Posturas do Município de Santa Maria regula os níveis de emissão de ruídos ou sons excessivos ou incômodos, regulando níveis aceitáveis de emissão, proibindo qualquer ruído que ultrapasse os níveis máximos permitidos. Esse código regula os níveis permitidos de emissão conforme as Zonas de Utilização da cidade.

\section{Questionários aos usuários}

Com a aplicação dos questionários nos sete espaços públicos de lazer da área central de Santa Maria obteve-se um total de 140 entrevistas. No que diz respeito ao perfil dos entrevistados, $54 \%$ era do sexo masculino e $46 \%$ do sexo feminino. $34 \%$ eram menores de 20 anos, $42 \%$ tinham entre 20 e 40 anos e $24 \%$ possuíam mais de 40 anos de idade. No quesito escolaridade, $35 \%$ possuíam o ensino fundamental, $45 \%$ o ensino médio e $20 \%$ o ensino superior. As perguntas realizadas aos usuários, que constam no Quadro 1, no item material e métodos, possuem suas respostas representadas pelas Figuras de número dois a oito. 
Rev. Elet. em Gestão, Educação e Tecnologia Ambiental (e-ISSN: 2236-1170)

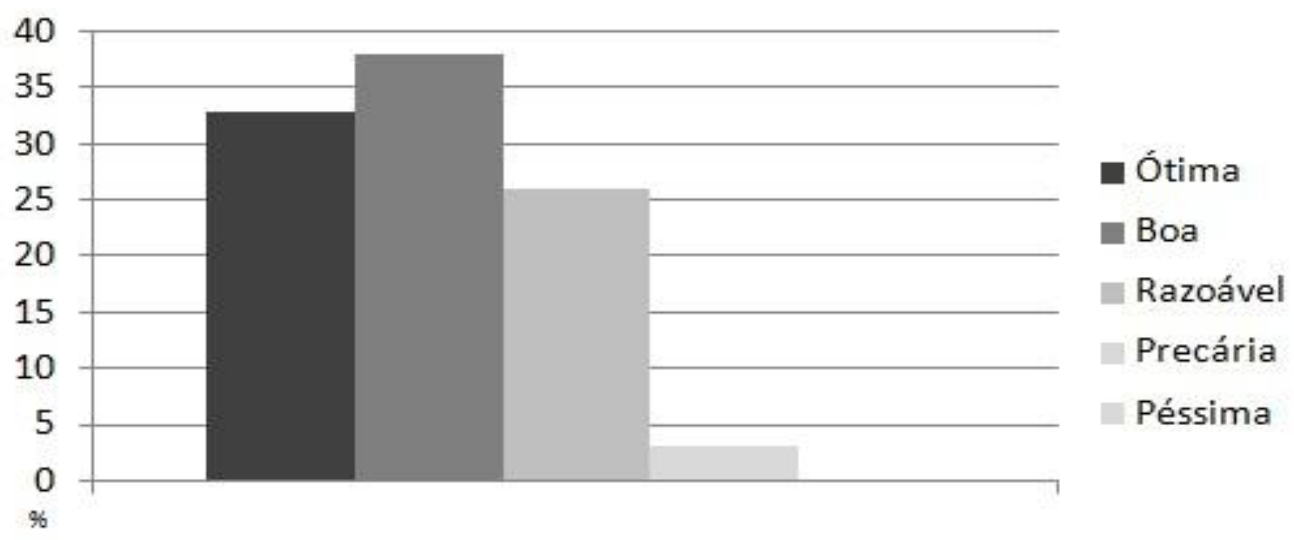

Figura 2. Resposta dos entrevistados quanto à classificação da arborização do centro urbano do município.

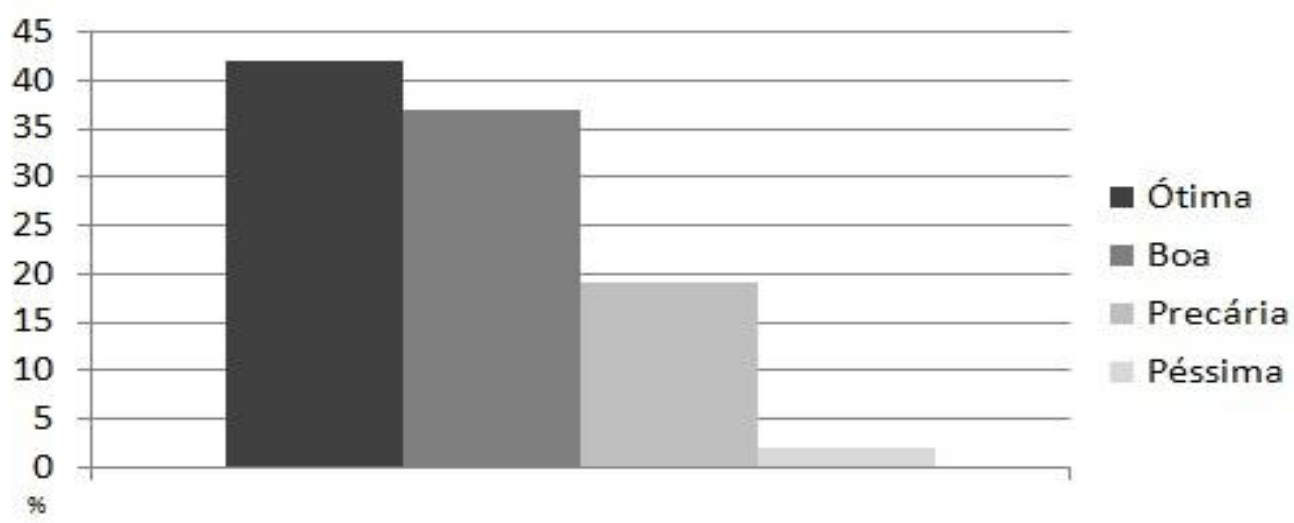

Figura 3. Resposta dos entrevistados quanto à satisfação em relação aos ambientes arborizados de Santa Maria.

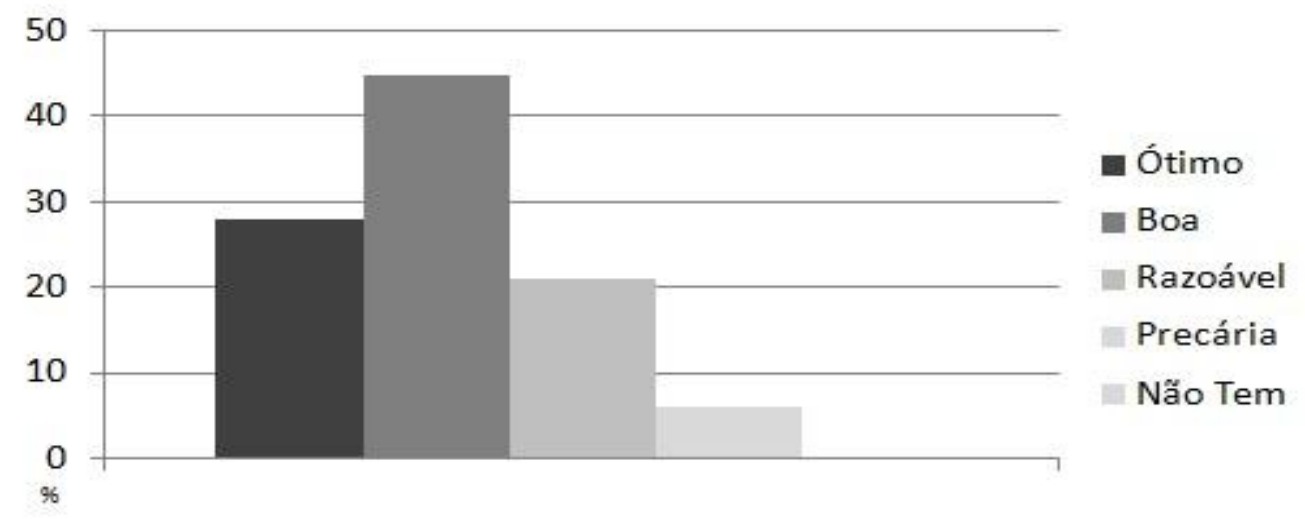

Figura 4. Resposta dos entrevistados quanto ao planejamento urbano das praças e espaços de lazer. 
Rev. Elet. em Gestão, Educação e Tecnologia Ambiental (e-ISSN: 2236-1170)

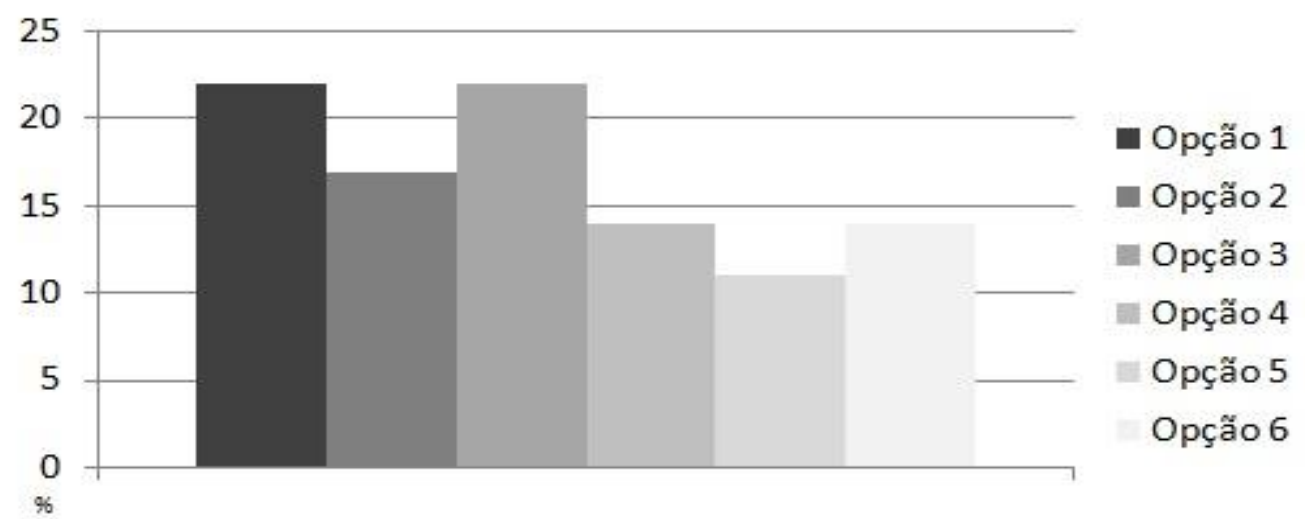

Figura 5. Resposta dos entrevistados quanto às vantagens de se ter espaços de lazer. Opção 1 sombra; opção 2 - redução do vento; opção 3 - redução da poluição sonora; opção 4 funciona como anti-stresse; opção 5 - aumenta a umidade atmosférica; opção 6 diminui o calor

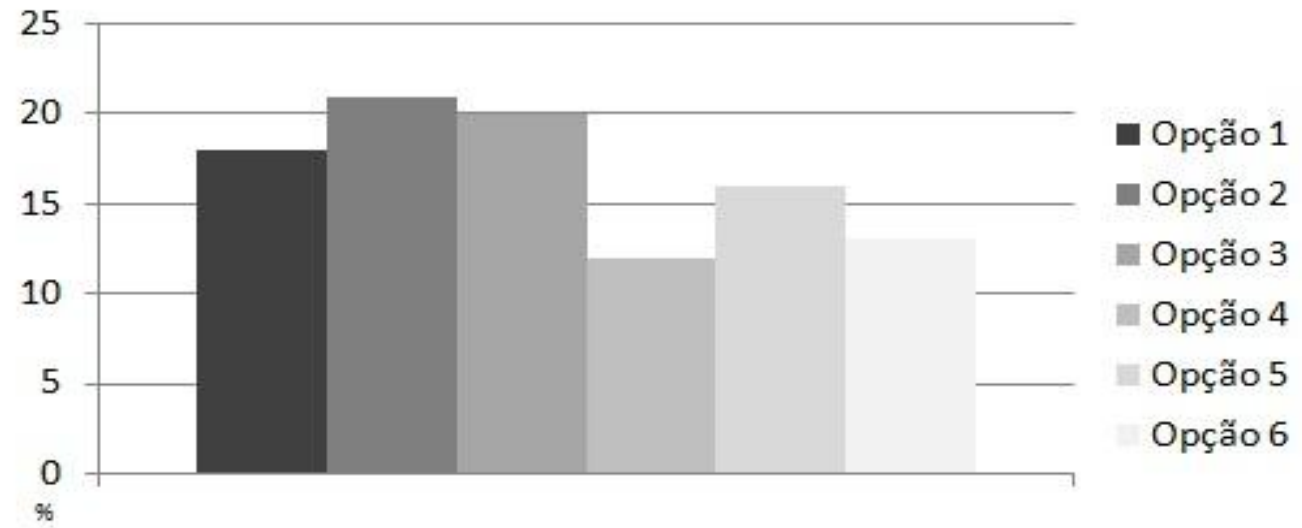

Figura 6. Resposta dos entrevistados quanto às desvantagens de se ter arborização urbana.

Opção 1- sujeira nas ruas e calçadas; opção 2 - sujeira provocada por pássaros; opção 3 redução da iluminação pública; opção 4 - problemas com a rede elétrica; opção 5 atrapalha os pedestres; opção 6 - causa acidentes em dia de temporal.

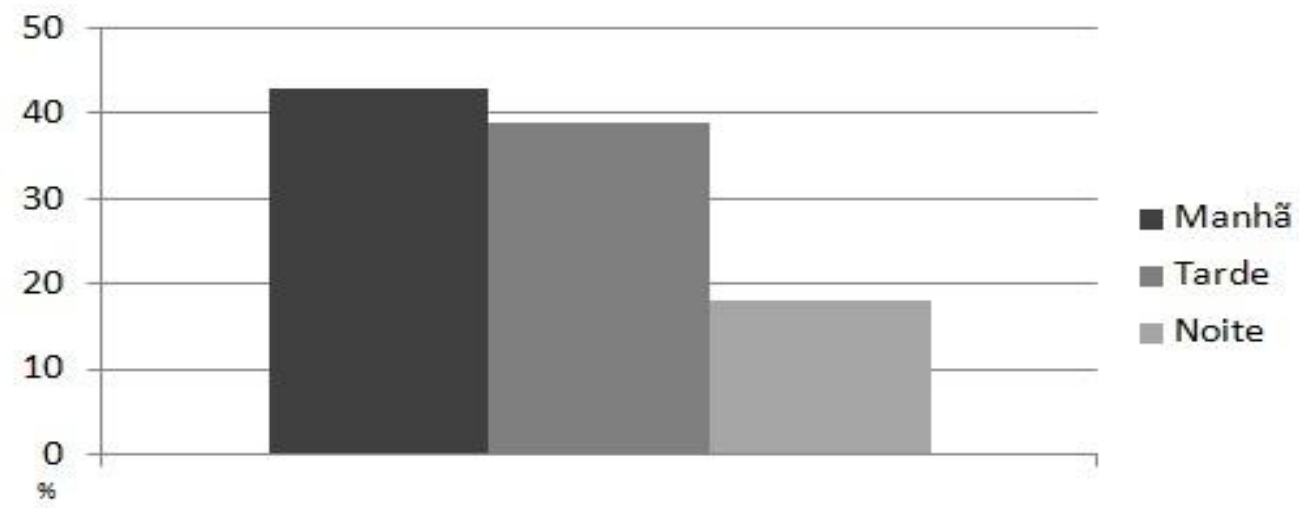

Figura 7. Resposta dos entrevistados quanto ao turno mais freqüentado pelos mesmos. 
Rev. Elet. em Gestão, Educação e Tecnologia Ambiental (e-ISSN: 2236-1170)

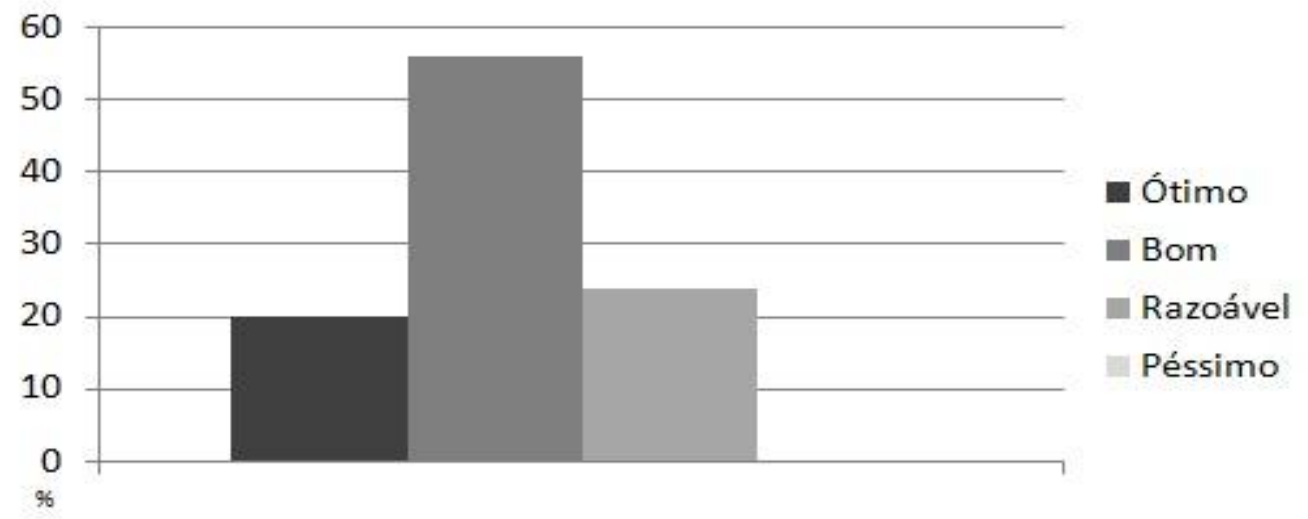

Figura 8. Resposta dos entrevistados quanto à satisfação sobre o nível de ruído nos espaços de lazer freqüentados.

\section{CONCLUSÕES}

Analisando os espaços públicos de lazer da área central de Santa Maria verificou-se, quanto aos aspectos físicos, que na Praça Saldanha Marinho, há existência de mobiliário importante como sanitários públicos, bancos e lixeiras, porém, constatam-se problemas na falta de bebedouros e placas informativas.

Os dados coletados quanto à satisfação dos usuários demonstram que $38 \%$ dos usuários classificam a arborização do centro urbano de Santa Maria boa, 56\% dos usuários se dizem satisfeitos em relação aos ambientes arborizados, $42 \%$ classificam como ótima a arborização dos espaços públicos determinados na pesquisa, $45 \%$ acha bom o planejamento da arborização central de Santa Maria.

Quanto às vantagens da arborização urbana, as três alternativas mais citadas pelos usuários foram à sombra, reduções do vento e redução da poluição sonora, e as desvantagens da arborização urbana foram às sujeiras nas ruas calçadas, sujeiras provocadas por pássaros e redução da iluminação pública.

O planejamento dos espaços públicos de lazer na cidade de Santa Maria parte de uma definição de recursos que é residual. A importância destinada às áreas verdes públicas sempre é reduzida, enquanto aumentam as necessidades reais criadas pela expansão urbana. Associada à esta questão está a falta de políticas públicas consistentes no campo urbanístico.

É nesse sentido que, embora a cidade apresente áreas verdes onde a população possa desfrutar de momentos de lazer e contato com a natureza, poucas têm esses espaços de forma organizada, de modo que não passam de espaços dispersos pela malha urbana.

A dinâmica e o desenvolvimento de Santa Maria e a capacidade para assegurar sua sustentabilidade resultam hoje do interesse dos mais diversos agentes políticos, entidades públicas e privadas, sociedade civil para gerir o processo de urbanização que deve ter o objetivo de proporcionar qualidade de vida aos seus habitantes.

Os resultados deste trabalho podem ser usados para contribuir no planejamento destes espaços e na qualidade de vida urbana de Santa Maria, para melhoria em futuras intervenções e revitalizações e base para futuros estudos nos demais espaços da cidade. 


\section{REFERÊNCIAS BIBLIOGRÁFICAS}

ASSOCIAÇÃO BRASILEIRA DE NORMAS TÉCNICAS. NBR 10151. Informação e documentação: trabalhos acadêmicos: apresentação. 1.e.d. Rio de Janeiro, 2000.

DREW, P. La realidad del espacio: la arquitectura de Martorell, Bohigas, Mackay, Puigdomènech. Barcelona: GG, 1993.

DUMAZEDIER, J. Lazer e Cultura Popular. São Paulo: Perspectiva, 1973.

FERREIRA, A. B. H. Novo Aurélio Século XXI: o dicionário da língua portuguesa. Rio de Janeiro: Nova Fronteira, 2003.

INSTITUTO BRASILEIRO DE GEOGRAFIA E ESTATÍSTICA - IBGE - (1 de julho de 2007). Disponível em <http://www.ibge.gov.br/>. Acesso em 11 abr. de 2010.

KLIASS, R. G. Parques urbanos de São Paulo. São Paulo: Pini, 1993.

LAMAS, J. M. R. G. Morfologia urbana e desenho da cidade. Lisboa: Fundação Calouste Gulbenkian, Junta Nacional de Investigação Científica e Tecnológica, 1990.

MORRIS, A. E. J. Historia de la forma urbana: desde sus orígenes hasta la revolución industrial. Barcelona: GG, 1984.

NECKEL, A. et al. Recuperación ambiental de un área verde urbana. Revista de Ciencia y Tecnologia, v. 11, n. 11, p. 19, 2009.

OLIVEIRA, P. T. S. B.; BITAR, O. Y. Indicadores ambientais para o monitoramento de parques urbanos. INTERFACEHS Revista de Gestão Integrada em Saúde do Trabalho e Meio Ambiente, v. 4, n. 2, p. 1-14, 2009.

PREFEITURA MUNICIPAL DE SANTA MARIA. Disponível em: <http://www.santamaria.rs.gov.br/>. Acesso em 11 abr. de 2010.

ROMERO, M. A. B. A arquitetura bioclimática do espaço público. Brasília: Editora Universidade de Brasília, 2001.

SCALISE, W. Parques Urbanos - evolução, projeto, funções e uso. Revista Assentamentos Humanos, Marília, v. 4, n. 1, p17-24, Out. 2002.

SILVA, L. J. M. Parques urbanos: a natureza na cidade - Uma análise da percepção dos atores urbanos. 2003. Dissertação (Mestrado em Gestão e Política Ambiental) - Centro de Desenvolvimento Sustentável, Universidade de Brasília, Brasília/DF, 2003.

ZAMORA, E. C. et al. Metodología para el estudio de los parques urbanos: la Comunidad de Madrid. Geofocus Revista Internacional de Ciência y Tecnología de la Informacion Geográfica, v. 3, n.3, p.160-185, junio 2003.

ZANIN, E. M. et al. Environmental Analysis and Zoning for an Urban Park Management Purpose. An International Journal: Brazilian Archives of Biology and Technology, v. 48, n. 4, p. 647-655, July 2005. 